\title{
Contexto competitivo, monitoramento ambiental e tomada de decisão estratégica: o caso dos micro e pequenos varejos da região do Barro Preto em Belo Horizonte
}

Paulo Henrique Oliveira

Mestre em engenharia de produção, na linha de pesquisa Competitividade e Estratégias Empresariais (UFMG).

E-mail: peagad@yahoo.com.br

Hélio Francisco da Conceita Ernesto João

Graduando em administração de empresas.

E-mail: hf_joao@yahoo.com.br

Nácer Samuel Abílio Mondlane

Graduando em administração de empresas.

E-mail: nacermondlane@yahoo.com.br

\section{Resumo}

Este artigo apresenta os resultados de pesquisa exploratória realizada no primeiro semestre de $2008 \mathrm{com}$ micro e pequenos empresários na região do Barro Preto em Belo Horizonte, importante pólo da moda mineira. Para a coleta de dados, optou-se pela utilização de um questionário estruturado, com perguntas fechadas, o qual foi aplicado a nove empresários da região, escolhidos a partir dos seguintes critérios: (a) acessibilidade dos pesquisadores às fontes de dados; (b) tempo disponível para a coleta de dados; (c) importância do empreendimento para a região. Por ser um tipo de pesquisa predominantemente quantitativa, técnicas estatísticas foram utilizadas nas análises dos dados coletados. Os resultados revelaram que, em contextos competitivos turbulentos, é aconselhável um processo de monitoramento contínuo dos movimentos dos concorrentes (diretos e indiretos) e das mudanças macroambientais, coletando informações úteis para uma tomada de decisão estratégica cada vez mais eficaz que favoreça a manutenção de vantagens competitivas significativas nos mercados em que os empreendimentos estão inseridos ao longo do tempo.

\section{Palavras-chave}

Monitoramento ambiental. Decisão estratégica. Micro e pequenos varejistas.

Competitive context, environmental monitoring and strategic decision making: the case of micro and small retails in the region of Barro Preto in Belo Horizonte

\begin{abstract}
TThis article presents the results of a wide research carried out in the first half of 2008 with micro and small entrepreneurs settled in the region of Barro Preto, an important center of fashion, in Belo Horizonte.

For data collection, a well structured questionnaire was used. Specific questions were addressed to nine regional entrepreneurs, accordingly selected, taking into consideration the following criteria: (a) easy access for the researchers to reach the data sources; (b) available time for data collection; and (c) important role of the entrepreneurship for the region. The results show that, in tumultuous competitive contexts, a process of continuous monitoring is advisable for (direct and/or indirect) movements of the competitors, as well as micro environmental changes, collecting useful information for a more and more strategic decision making which will favor maintaining relevant competitive advantages in those markets where entrepreneurships are inserted as time goes by.
\end{abstract}

Keywords

Environmental monitoring. Strategic decision. Micro and small retailers.

\section{ASPECTOS INTRODUTÓRIOS}

O presente estudo analisa o comportamento informacional na tomada de decisão estratégica dos micro e pequenos empresários do setor varejista instalados na região do Barro Preto em Belo Horizonte. No contexto desta pesquisa, comportamento informacional significa a identificação e o uso de fontes de informação a partir do processo de monitoração ambiental, utilizadas pelos empresários para a tomada de decisões estratégicas em diferentes contextos competitivos. Para a configuração do ambiente competitivo, foram adaptados os estudos de Duncan (1972) e Mintzberg (2003) sobre tipologias ambientais, normalmente utilizadas para determinar o nível de incerteza do ambiente organizacional a partir da análise das dimensões complexidade (simplescomplexo) e dinamicidade (estático-dinâmico). Acreditase que o nível de incerteza ambiental afeta a frequência de uso e a importância dada pelos gestores às fontes de informação utilizadas em seus processos de decisão estratégica sobre o ambiente competitivo. Para uma visão sistêmica do escopo dessa pesquisa, a figura 1 foi delineada tendo como parte central o desempenho organizacional (DO).

\section{FIGURA 1}

Visão sistêmica do escopo da pesquisa

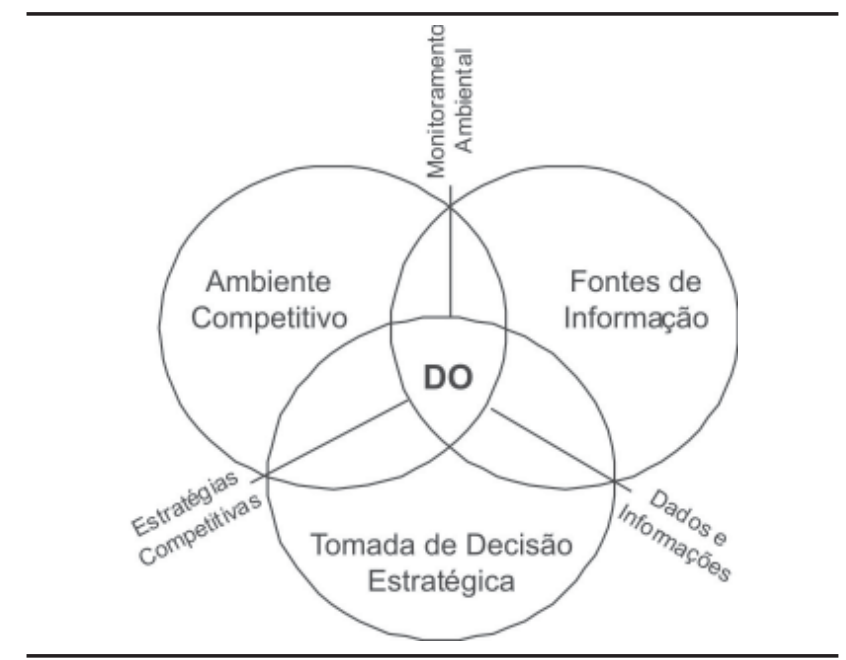

Fonte: autores da pesquisa. 
A escolha do varejo da região do Barro Preto se justifica pela sua importância para a economia local e pela atual concorrência que tem afetado o desempenho do setor como um todo, além dos fatores macroambientais. Assim, a região do Barro Preto, por concentrar grande número de lojas que comercializam roupas, sapatos e acessórios diversos, assume especial atenção para esta pesquisa. Está localizada na região centro-sul da capital mineira, atendendo principalmente a lojistas (atacado), apesar de haver algumas lojas que vendem no varejo (FECOMÉRCIO Minas, 2008).

Para ressaltar a complexidade e a dinamicidade do ambiente de negócios pelas quais passam as empresas do comércio varejista mineiro, foi utilizado um estudo realizado pela Federação do Comércio do Estado de Minas Gerais (FECOMÉRCIO Minas, 2008), o qual demonstra que o setor de vestuário mineiro tem apresentado reduções significativas em seu faturamento real, chegando a uma queda acumulada de $13,51 \%$ nos últimos 12 meses. Em termos do ambiente de negócios, o relatório ainda adverte que:

para o lojista permanecerá o desafio de atuar estrategicamente no decorrer de $2008 \mathrm{em}$ face da concorrência desleal; das eleições municipais acompanhadas por possíveis conturbações de ordem política; da incerteza econômica internacional; da manutenção de juros reais elevados; da carga tributária pesada; dos riscos inerentes de uma política de crédito facilitado; do nível de endividamento do consumidor; da inadimplência; com vistas na criação de oportunidades que possam gerar uma margem lucrativa maior e a fidelização do cliente com vistas na efetivação de vendas futuras (FECOMÉRCIO Minas, 2008, p.5).

Neste contexto, este estudo apresenta os resultados de uma pesquisa exploratória realizada no primeiro semestre de 2008 com micro e pequenos empresários do ramo de vestuário, instalados na região do Barro Preto em Belo Horizonte, considerado importante pólo da moda mineira. Para a coleta de dados sobre o contexto competitivo e as fontes de informações utilizadas por esses empresários no processo de monitoração dos seus ambientes competitivos, optou-se pela utilização de um questionário estruturado, o qual foi aplicado a nove empresários da região, escolhidos intencionalmente a partir dos seguintes critérios: acessibilidade dos pesquisadores às fontes de dados, tempo disponível para a coleta e importância do empreendimento para a região. Por ser um tipo de pesquisa predominantemente quantitativa, técnicas estatísticas foram utilizadas nas análises dos dados coletados, não excluindo o uso de outras técnicas de análise para melhor compreensão e delimitação do problema em questão.

Para atingir o objetivo proposto para esta pesquisa, que foi o de analisar o uso de fontes de informação pelos micro e pequenos empresários do comércio varejista (ramo de vestuário) para a tomada de decisão estratégica, os seguintes temas foram abordados: ambiente organizacional, levando-se em consideração os estudos sobre as dimensões ambientais (macro e microambiente); as tipologias existentes para se analisar a sua incerteza e o processo de monitoração ambiental, focando-se nos tipos de fontes de informação sobre os competidores mais utilizadas e disponíveis interna ou externamente para os tomadores de decisões estratégicas.

Por ser uma pesquisa de natureza exploratória, espera-se como resultado principal compreender o comportamento informacional dos micro e pequenos empresários na tomada de decisão estratégica, além de contribuir para futuras pesquisas acadêmicas sobre os temas abordados. É importante ressaltar que este estudo não teve a pretensão de esgotar o assunto em questão, que, por sinal, é bastante amplo e complexo, mas sim trazer à baila a necessidade de reflexão contextualizada sobre a seleção e o uso eficaz de fontes de informação sobre o ambiente competitivo (concorrentes) e a sua importância para a eficácia do processo de tomada de decisão estratégica organizacional de micro e pequenos empreendedores do setor varejista instalados na região do Barro Preto em Belo Horizonte.

\section{REVISÃO BIBLIOGRÁFICA}

O ambiente externo: mapeando a incerteza ambiental

Em termos estruturais, autores como Daft (2002) e Mintzberg (2003) têm analisado o ambiente a partir da sua divisão em duas dimensões básicas: macroambiente (ou ambiente geral) e microambiente (ou ambiente de tarefas). Na primeira, estão todas as variáveis que afetam indiretamente o funcionamento da organização. São exemplos as condições políticas, regulatórias e econômicas de um país ou região, as inovações e transferências tecnológicas, os valores culturais, sociais e demográficos de uma população e as questões ecológicas a que as organizações estão submetidas (DAFT, 2002).

Em contrapartida, em uma dimensão mais próxima da organização, estão os elementos do microambiente que 
afetam diretamente e no curto prazo o funcionamento e a gestão organizacional, sendo representados, principalmente, pelos competidores, consumidores, fornecedores, instituições financeiras e grupos de ações especiais, como sindicatos e organizações nãogovernamentais (ONGs). A figura 2 ilustra o ambiente e as suas dimensões.

Na visão de Nadler, Gerstein e Shaw et alii (1993), o ambiente pode afetar o funcionamento da organização de três maneiras: pela exigência de novos produtos ou serviços, por meio de limitações à ação organizacional como escassez de capital ou de tecnologia; pela oferta de oportunidades a serem exploradas pela organização. Para autores como D'Aveni (1995), Mintzberg (2003), Porter (1980) e Hamel e Prahalad (1994), a existência de muitos fatores ambientais leva à incerteza ambiental, colocando em risco a capacidade de sobrevivência e o crescimento das organizações nos mercados em que atuam ao longo do tempo (BUCHKO, 1994).

Estudos sobre a incerteza ambiental têm permeado o meio acadêmico e empresarial há muito tempo. Desde as pesquisas de autores contingenciais, como Chandler (1962), Burns e Stalker (1961), Lawrence e Lorsch (1967) e Emery e Trist (1965), que abordaram e reconheceram a influência do ambiente sobre estratégias, estruturas e processos organizacionais, até os dias de hoje, com os estudos de Mintzberg (2003), Choo (1995) e Nonaka e Takeushi (1997), não se esquecendo de Dill (1958), Aguilar (1967) e Duncan (1972) sobre o uso da informação e do conhecimento com insumos para a tomada de decisão voltada para o processo de adaptação organizacional ao seu contexto de negócios, percebe-se que, para ter sucesso, a organização precisa desenvolver continuamente formas de se adaptar continuamente às mudanças que ocorrem em seus ambientes de negócios, que estão cada vez mais complexos, dinâmicos e imprevisíveis (D'AVENI, 1995; MINTZBERG, 2003). Em termos conceituais, entenda-se por complexidade o número de elementos do ambiente que influencia direta ou indiretamente a organização e, por dinamicidade, a velocidade de mudança dessas variáveis em certo período de tempo (DUNCAN, 1972; MINTZBERG, 2003).

A figura 3 ilustra uma tipologia para analisar o nível de incerteza de um ambiente a partir da análise das dimensões complexidade (simples-complexo) e dinamicidade (estático-dinâmico) proposta por Duncan (1972). A primeira revela um ambiente simples-dinâmico. Simples, porque existem poucos competidores, e dinâmico, porque esses competidores mudam com grande freqüência no tempo, seja pela inserção de estratégias inovadoras, seja pela entrada e saída constante de competidores do ambiente. Nesse tipo de ambiente, a incerteza é classificada como alta-moderada. O segundo ambiente é o simples-estável. Simples, por existirem poucos competidores no ambiente, e estável, porque esses competidores não mudam com frequência ao longo do tempo.

\section{FIGURA 2}

$\mathrm{O}$ ambiente externo organizacional: principais elementos

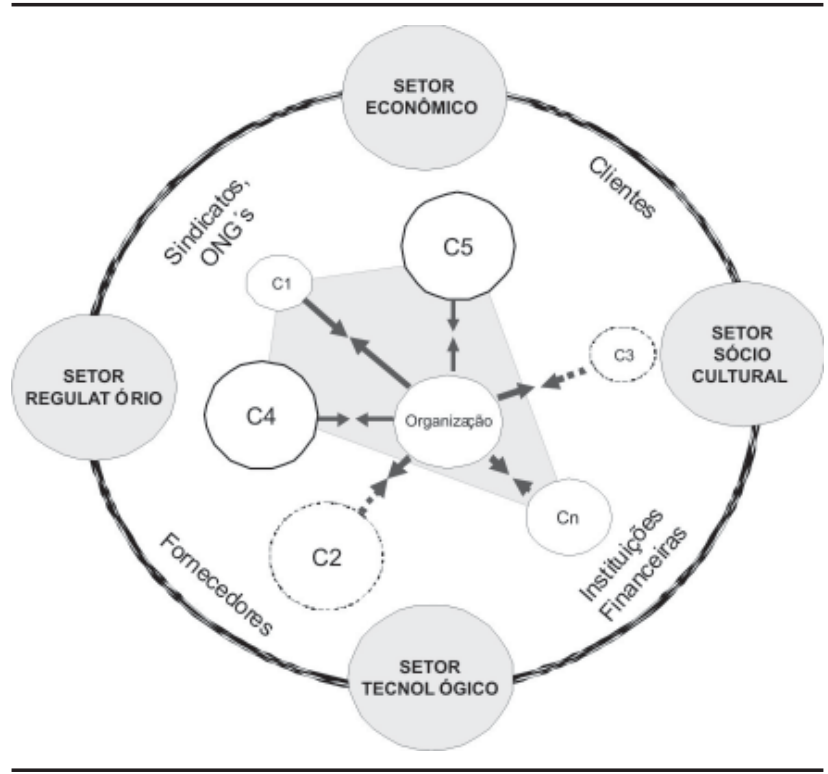

Fonte: adaptado de Daft (2002) e Mintzberg (2003).

FIGURA 3

Mapeando a incerteza ambiental: o modelo de Duncan

\begin{tabular}{|c|c|}
\hline \multicolumn{2}{|c|}{ Simples } \\
\hline Campo 01 & Campo 03 \\
\hline $\begin{array}{l}\text { Reduzida percep ção da } \\
\text { incerteza }\end{array}$ & \multirow{2}{*}{$\begin{array}{l}\text { Percepção moderadamente } \\
\text { elevada da incerteza } \\
\text { - Pequeno número de fatores e } \\
\text { componentes no ambiente. } \\
\text { - Os fatores e componentes sōo um } \\
\text { tanto semelhantes entre si. } \\
\text { - Os fatores e os componentes eståo } \\
\text { em confinuo processo de mudarç c }\end{array}$} \\
\hline $\begin{array}{l}\text {-Pequeno número de fatores e } \\
\text { componentes no ambiente. } \\
\text { - Os fatores e componentes são um } \\
\text { tanto semelhantes entre si. } \\
\text { - Os fatores e os componentes } \\
\text { permanecem basicamente os } \\
\text { mesmos e nāo mudam. }\end{array}$ & \\
\hline \multicolumn{2}{|l|}{ Estático - } \\
\hline Campo 02 & Campo 04 \\
\hline $\begin{array}{c}\text { Percep ção moderadamente } \\
\text { reduzida da incerteza }\end{array}$ & $\begin{array}{c}\text { Elevada percepçāo da } \\
\text { incerteza }\end{array}$ \\
\hline $\begin{array}{l}\text { - Grande número de fatores e } \\
\text { componentes no ambiente. } \\
\text { - Os fatores e componentes não são } \\
\text { semelhantes entre si. } \\
\text { - Os fatores e os componentes } \\
\text { permanecem basicamente os } \\
\text { mesmos.. }\end{array}$ & $\begin{array}{l}\text { - Grande número de fatores e } \\
\text { componentes no ambiente. } \\
\text { - Os fatores e componentes nōo sōc } \\
\text { um tanto semelhantes enfre si. } \\
\text { - Os fatores e os componentes estão } \\
\text { em continuo processo de mudançc }\end{array}$ \\
\hline \multicolumn{2}{|c|}{ Complexo } \\
\hline
\end{tabular}

Fonte: adaptado de Duncan (1972). 
Nesse ambiente, a incerteza é classificada como baixa. No terceiro ambiente, é considerada a dimensão complexo-estável. Complexo, por existirem muitos competidores, e estável, porque eles não mudam com grande frequência ao longo do tempo. Nessas condições, a incerteza é classificada como baixa-moderada. E, finalmente, na última configuração, tem-se um ambiente complexo-dinâmico. Pelas mesmas razões anteriores, complexo, por ter muitos competidores, e dinâmico, porque eles mudam com grande frequência ao longo do tempo. Nesse cenário, a incerteza é considerada alta.

\section{Monitoramento ambiental e fontes de informação}

Monitoramento ambiental (environmental scanning) tem sido normalmente definido na literatura como o processo de aquisição e uso da informação sobre fatos, eventos, tendências e relacionamentos existentes entre as variáveis do ambiente externo que afetam direta ou indiretamente o desempenho organizacional ao longo do tempo. Autores como Aguilar (1967), Auster e Choo (1994) têm contribuído significativamente para o entendimento e o desenvolvimento desse ramo do conhecimento, fornecendo insights significativos para melhor tomada de decisão por meio da compreensão do ambiente com os quais as organizações realizam as suas atividades de troca de insumos, energias e informações por bens e serviços, mediante agregação de valor e sua posterior disponibilização ao mercado consumidor.

Sutton (1988), por exemplo, argumenta que o mapeamento do ambiente propicia à organização melhor compreensão dos movimentos das forças externas, além de fornecer as informações necessárias para que ela responda efetivamente a essas mudanças na tentativa de assegurar melhor e permanente posição nos mercados em que atua. Para esse autor, as organizações monitoram seus ambientes a fim de evitar surpresas, para identificar ameaças e oportunidades, obter vantagens competitivas e dar suporte aos processos de inteligência competitiva, planejamento e administração estratégica de curto e longo prazos.

Em termos processuais, Moresi (2001) indica cinco passos para um processo de monitoração ambiental. Para ele, na etapa inicial, a organização deve procurar por recursos de informação. Em seguida, deve selecionar os recursos de informação que sejam monitoráveis e partir para a identificação dos critérios de monitoração. Após a escolha dos critérios, vem a atividade de monitoração propriamente dita e, por último, os responsáveis pelo processo de monitoração ambiental devem projetar um sistema de controle para a determinação das ações especiais ou corretivas a serem tomadas ante os resultados indesejáveis alcançados pela monitoração.Para um processo de monitoramento eficaz, é preciso identificar as necessidades de informações no contexto decisório da organização e de onde elas serão obtidas (HAMBRICK, 1982). A escolha adequada de fontes de informação é fator crítico para a eficiência e a eficácia das decisões tomadas (MORESI, 2001).

Na literatura, as fontes de informações são classificadas de diversas maneiras e critérios diferentes, como, por exemplo, pela sua origem, estruturação ou pelos meios e recursos que lhes dão suporte. Sutton (1988), apud Barbosa (2002), por exemplo, em pesquisa realizada com gerentes norte-americanos, identificou alguns dos principais tipos de fontes de informação normalmente utilizadas pelos gerentes em seus processos decisórios, as quais estão reproduzidas no quadro 1.

Na mesma linha de raciocínio, Auster e Choo (1994), apud Barbosa (2002), também realizaram um estudo com executivos canadenses no setor de telecomunicações, no qual foram identificados quatro tipos de fontes de informação bastante utilizadas e atualmente: (a) fontes externas - pessoais e impessoais; (b) fontes internas pessoais e impessoais, conforme demonstrado no quadro 2, a seguir.

\section{QUADRO 1}

Fontes de informações

\begin{tabular}{l|l}
\hline $\begin{array}{l}\text { Fontes de } \\
\text { informações }\end{array}$ & Exemplos \\
\hline Internas & $\begin{array}{l}\text { Setores de vendas, de pesquisa mercadológica, } \\
\text { de planejamento, de engenharia, de compras, } \\
\text { análise de produtos concorrentes, ex- } \\
\text { empregados de concorrentes. }\end{array}$ \\
$\begin{array}{l}\text { Contatos diretos } \\
\text { negócios }\end{array}$ & $\begin{array}{l}\text { Clientes, encontros, demonstrações de vendas, } \\
\text { distribuidores, fornecedores, associações } \\
\text { comerciais, consultores, varejistas, empregados } \\
\text { dos concorrentes, agências de publicidade. }\end{array}$ \\
$\begin{array}{l}\text { Informações } \\
\text { publicadas }\end{array}$ & $\begin{array}{l}\text { Periódicos do setor, material promocional das } \\
\text { empresas, relatórios anuais, relatórios de } \\
\text { analistas financeiros, periódicos financeiros, } \\
\text { discursos dos gerentes, periódicos de negócios, } \\
\text { jornais nacionais e locais, diretórios, } \\
\text { publicações governamentais. }\end{array}$ \\
\hline $\begin{array}{l}\text { Onalistas financeiros, bases de dados } \\
\text { eletrônicas, bancos de investimentos e } \\
\text { comerciais, anúncios. }\end{array}$ \\
\hline
\end{tabular}

Fonte: Sutton (1988), apud Barbosa (2002). 
Daft e Lengel (1986) também categorizaram as fontes em informação em interna e externa. Segundo eles, algumas fontes externas podem ser os periódicos e jornais da área comercial, amigos na indústria, clientes, entre outros. Internamente, as fontes citadas pelos autores foram as reuniões formais e não agendadas e os passeios pela empresa, entre outras. Borges (1995) complementa esses estudos ao apresentar algumas das principais fontes de informações que poderão ser utilizadas pelas organizações, como, por exemplo, as suas equipes de vendas e de engenharia, os fornecedores, as agências de publicidade, os próprios concorrentes, como também, as associações comerciais e as empresas de pesquisas mercadológicas, entre outras.

Como se pôde perceber, a seleção e o uso apropriado de fontes de informações podem ajudar os executivos a tomar decisões estratégicas. Manter um processo de monitoramento contínuo do ambiente competitivo ajuda a organização a evitar surpresas desagradáveis e prover novas oportunidades de negócios, condições essenciais para a sobrevivência e o crescimento organizacional nos mercados em que atuam em tempos de grande hostilidade e turbulência competitiva (BARBOSA, 1997).

\section{PROCEDIMENTOS METODOLÓGICOS}

Para a consecução do objetivo principal desta pesquisa, que partiu da necessidade de analisar o comportamento informacional dos responsáveis pela tomada de decisão estratégica de micro e pequenas empresas, optou-se pela pesquisa exploratória, que, segundo Collins e Hussey (2005, p.24), tem como foco

obter insights e familiaridade com a área do assunto para investigações mais rigorosas num estágio posterior. [...] Os dados compilados costumam ser quantitativos e técnicas estatísticas são geralmente utilizadas para resumir as informações.

A escolha da pesquisa exploratória derivou-se da necessidade de se averiguar, por meio de um levantamento quantitativo e análises estatísticas, a situação atual das práticas de monitoramento do ambiente competitivo exercido por empresários da região do Barro Preto, buscando-se identificar padrões ou hipóteses para futuras pesquisas sobre o tema em questão.
QUADRO 2

Fontes de informação organizacional

\begin{tabular}{|c|c|c|}
\hline Fontes & Pessoais & Impessoais \\
\hline Externas & $\begin{array}{l}\text { - Clientes } \\
\text { - Concorrentes } \\
\text { - Contatos } \\
\text { profissionais } \\
\text { - Contatos comerciais } \\
\text { - Funcionários de } \\
\text { órgãos governamentais }\end{array}$ & $\begin{array}{l}\text { - Jornais e periódicos } \\
\text { - Publicações } \\
\text { governamentais } \\
\text { - Rádio e televisão } \\
\text { - Associações comerciais e } \\
\text { industriais } \\
\text { - Conferências e viagens }\end{array}$ \\
\hline Internas & $\begin{array}{l}\text { - Superiores } \\
\text { - Subordinados } \\
\text { - Equipes de } \\
\text { funcionários }\end{array}$ & $\begin{array}{l}\text { - Memorandos e circulares } \\
\text { internos } \\
\text { - Relatórios e estudos } \\
\text { internos } \\
\text { - Biblioteca da organização } \\
\text { - Serviços de informação } \\
\text { eletrônica. }\end{array}$ \\
\hline
\end{tabular}

Fonte: adaptado de Auster e Choo (1994), apud Barbosa (2002).

Partindo de um paradigma positivista, utilizou-se uma pesquisa predominantemente quantitativa com aplicação de questionário estruturado a nove empreendedores. Por ser uma amostra relativamente pequena, os questionários foram aplicados pelos próprios pesquisadores no período de 25 de março a 20 de abril de 2008, abordando temas como o número de concorrentes diretos e indiretos, a dinâmica de entrada e saída de concorrentes nos últimos 10 anos no mercado local, o comportamento dos concorrentes no lançamento de novos bens e/ou serviços, as barreiras de entradas existentes no mercado local e as principais fontes de informações utilizadas pelos empreendedores para monitorar os movimentos, tendências e relacionamentos que acontecem em seus ambientes competitivos. Conforme explicitado em seções anteriores, as empresas foram selecionadas intencionalmente a partir dos seguintes critérios: importância do empreendimento para a região; acesso dos pesquisadores à fonte de dados e o tempo disponível para a coleta dos dados.

É importante destacar que, para esta pesquisa, foi considerado apenas o ambiente competitivo da organização, composto exclusivamente pelos seus concorrentes diretos e indiretos, o que não descarta a importância de se considerarem as demais variáveis ambientais em pesquisas futuras, como aquelas decorrentes das situações políticas, econômicas, tecnológicas e sociais que compõem o macroambiente organizacional, entre outras. 


\section{APRESENTAC̣ÃO E ANÁLISE DOS DADOS}

Da análise do ambiente competitivo (complexidade versus dinamicidade)

Para a análise do ambiente competitivo, foram adaptados os modelos de Duncan (1972) e Mintzberg (2003) sobre a incerteza ambiental. A partir da análise da concorrência direta e indireta e da sua movimentação no mercado competitivo, os dados foram compilados dando origem aos gráficos a seguir.

\section{GRÁFICO 1}

Complexidade e dinâmica do ambiente competitivo na perspectiva dos empresários
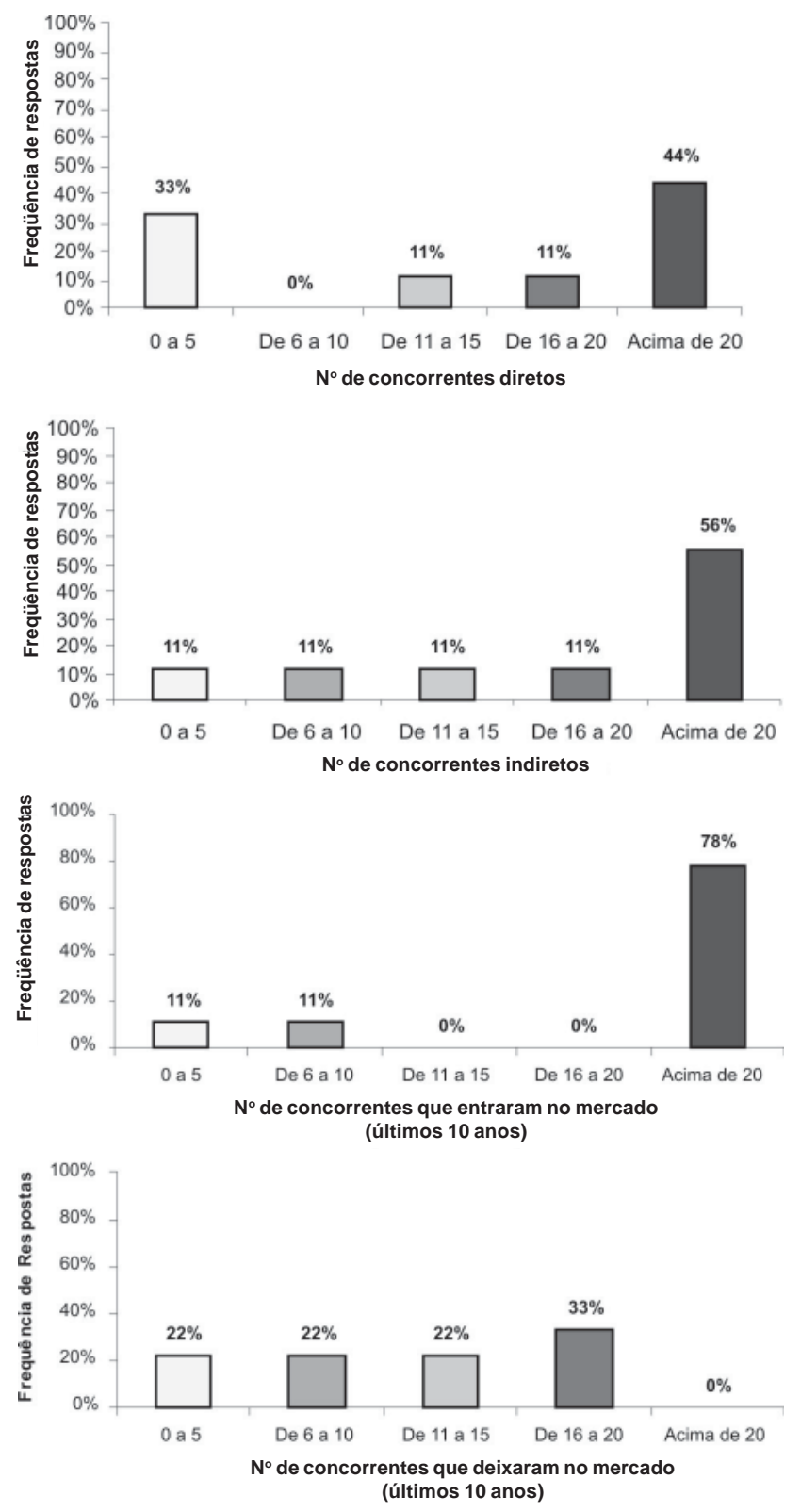

Fonte: dados da pesquisa.

Ci. Inf., Brasília, v. 37, n. 2, p. 110-121, maio/ago. 2008
GRÁFICO 2

Freqüência de lançamento de novos produtos no mercado competidor

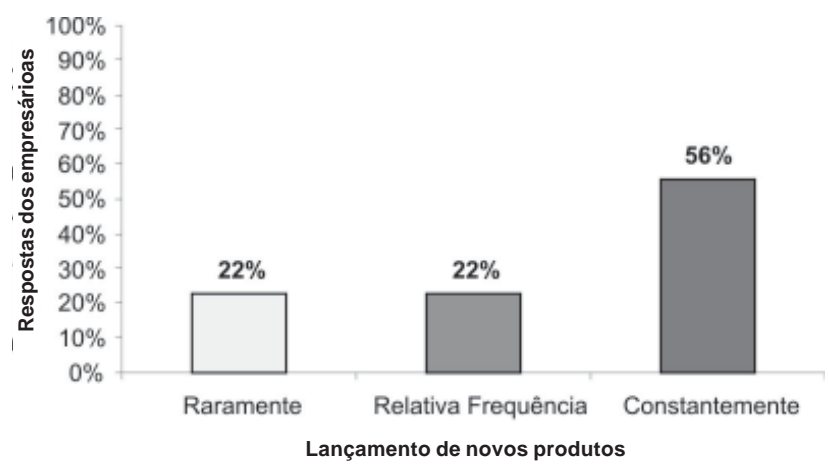

Fonte: dados da pesquisa.

\section{GRÁFICO 03}

Barreiras de entrada no mercado na perspectiva dos empresários

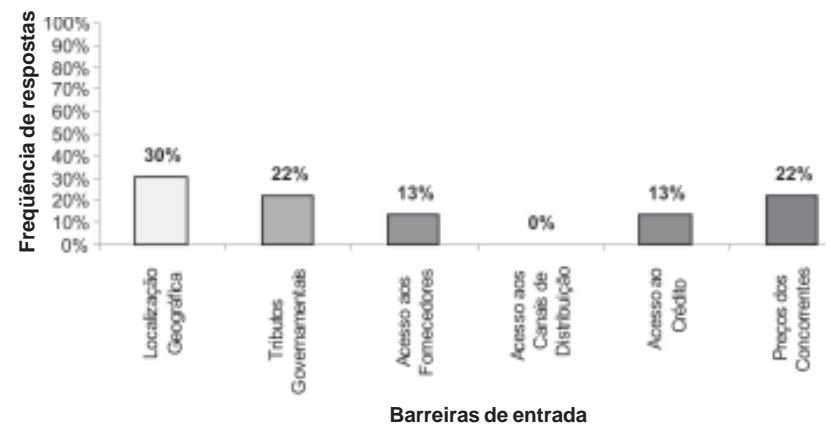

Fonte: dados da pesquisa.

Pela análise dos gráficos 1,2 e 3 , percebe-se que o ambiente competitivo no qual os micro e pequenos empreendedores estão inseridos apresenta complexidade relativamente grande, comprovada pela constatação da maioria dos pesquisados. Cerca de $44 \%$ informaram que têm mais de 20 concorrentes diretos, e $68 \%$, mais de 20 indiretos. Para 68\%, mais de 20 concorrentes (diretos e indiretos) deixaram o mercado nos últimos 10 anos, e, para $38 \%$, entraram no mesmo mercado entre 16 e 20 competidores no período de 10 anos. Outro dado importante revela que, para 56\% dos empresários, seus competidores estão sempre lançando novos produtos (bens e serviços). Finalmente, em termos de barreira de entrada no setor, houve uniforme distribuição da percepção dos empresários, destacando-se a localização geográfica como a principal barreira (33\%), seguida pelos tributos governamentais e pelos preços dos competidores (22\% cada). 
Em síntese, pode-se concluir que esse ambiente competitivo no qual esses empreendedores estão inseridos apresenta as características de um ambiente complexo, dinâmico e imprevisível, necessitando de um processo de monitoramento constante das variáveis que o compõem, conforme sugerido por autores como Duncan (1972), Mintzberg (2003) e Aguilar (1967), que abordam os temas incerteza e monitoramento ambiental, respectivamente.

\section{Da análise do comportamento informacional}

Partindo-se da análise da percepção dos empreendedores sobre o seu ambiente competitivo, a segunda fase buscou investigar o comportamento informacional (freqüência de uso de fontes de informações - diária, semanal, quinzenal, mensal, bimestral, trimestral, quadrimestral, semestral, anual e esporádica) de tais empreendedores, solicitando-lhes que indicassem as fontes de informações mais utilizadas para a tomada de decisão estratégica, conforme ilustrado pela tabela 1 .

Os dados da tabela 1 revelaram que, diariamente, clientes (29\%), amigos, parentes e conhecidos (21\%), jornais impressos (14\%) e os funcionários da própria empresa (14\%) constituem-se as principais fontes de informações para a tomada de decisão. Semanalmente, para 33\% dos entrevistados, as revistas especializadas configuram-se como a principal fonte de informação. Outro dado importante releva que 33\% dos entrevistados participam de feiras quinzenalmente, coletando dados e informações para os seus negócios. Em termos mensais, houve equilíbrio entre as fontes de informação. Com 13\% apareceram fontes como televisão, rádio, jornais impressos, revistas especializadas, participação em feiras e eventos, amigos, conhecidos e parentes, clientes e fornecedores.

Em síntese, verifica-se que, quanto maior for o período de tempo, menor o uso das fontes de informações pelos empreendedores. Talvez essa conclusão venha comprovar a grande incerteza existente no setor, que induz os empresários a manter contínuo fluxo de coleta de informações sobre o seu ambiente competitivo em curtos espaços de tempo. É importante ressaltar que os dados coletados não permitem inferir conclusões satisfatórias sobre os motivos que levam os empreendedores a dispensar pouca importância para tais fontes, o que poderá ser mais bem explorado por pesquisas futuras. Relatórios de agências governamentais, funcionários de empresas concorrentes, os fornecedores e funcionários de empresas não concorrentes são as fontes menos utilizadas pelos empresários.

Conforme dados e disponibilizados na tabela 2, a seguir, percebe-se que os clientes (56\%) e os funcionários da própria empresa (44\%) são as fontes mais importantes para os gestores para tomada de decisão estratégica, seguidas pela televisão, rádio, participação em feiras e eventos, amigos, parentes e conhecidos com $33 \%$ cada um e com $22 \%$ as revistas especializadas. Os valores somam mais de $100 \%$, porque os respondentes puderam assinalar mais de uma opção. Destaca-se que os estudos setoriais do governo, funcionários de outras empresas (não concorrentes), funcionários dos concorrentes, especialistas do ramo e os fornecedores não são as fontes

TABELA 1

Fontes de informação e freqüência de uso

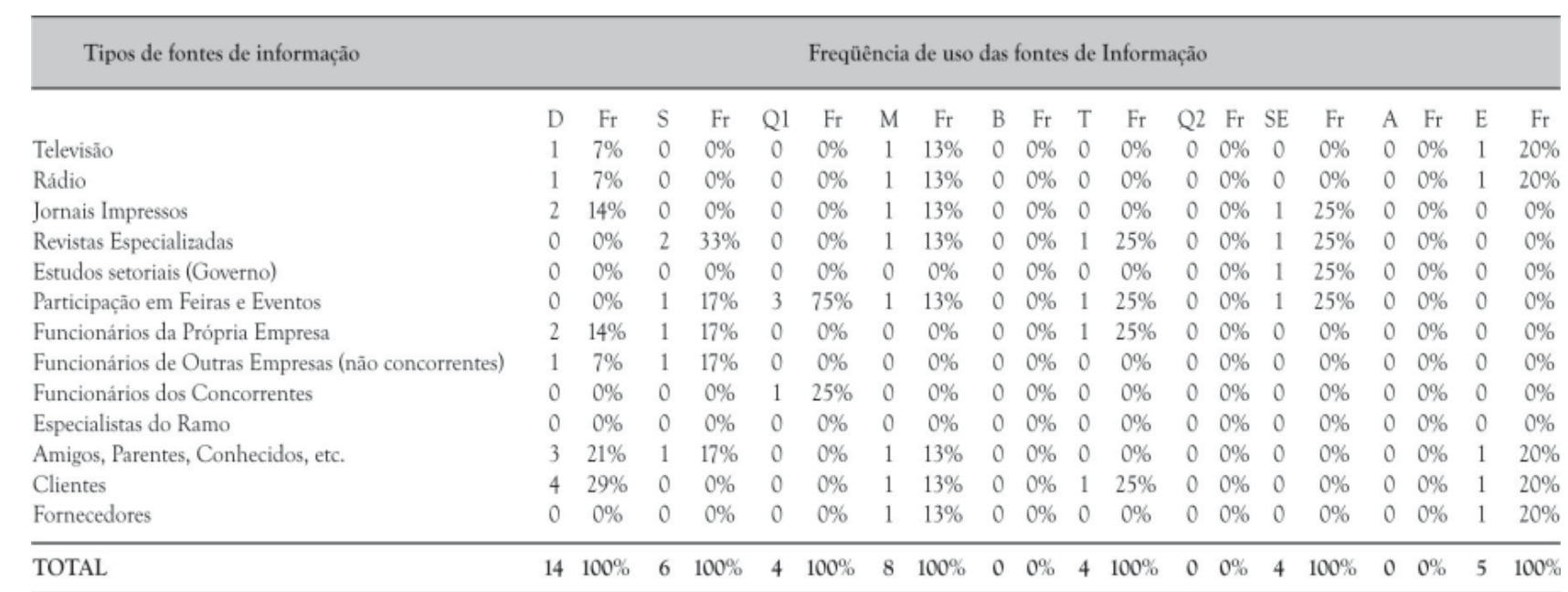

Fonte: dados da pesquisa. 
de informações mais importantes para a decisão estratégica. Ao contrário, foram consideradas de média para baixa importância. Para os gestores, os especialistas do setor não representam nenhuma importância para a consecução de suas estratégias competitivas. Sugere-se que essa conclusão também seja aprofundada em futuras pesquisas.

TABELA 2

Fontes de informação e importância para as estratégias competitivas

\begin{tabular}{|c|c|c|c|c|c|c|c|c|c|c|}
\hline \multirow[t]{2}{*}{ Tipos de fontes de informação } & \multicolumn{10}{|c|}{ Importância para as estratégias competitivas } \\
\hline & 1 & $\mathbf{F r}$ & 2 & $\mathbf{F r}$ & 3 & Fr & 4 & $\mathbf{F r}$ & 5 & $\mathbf{F r}$ \\
\hline Televisão & 0 & $0 \%$ & 0 & $0 \%$ & 0 & $0 \%$ & 0 & $0 \%$ & 3 & $33 \%$ \\
\hline Rádio & 0 & $0 \%$ & 0 & $0 \%$ & 0 & $0 \%$ & 0 & $0 \%$ & 3 & $33 \%$ \\
\hline Jornais Impressos & 0 & $0 \%$ & 0 & $0 \%$ & 0 & $0 \%$ & 3 & $33 \%$ & 1 & $11 \%$ \\
\hline Revistas Especializadas & 0 & $0 \%$ & 0 & $0 \%$ & 2 & $22 \%$ & 1 & $11 \%$ & 2 & $22 \%$ \\
\hline Estudos setoriais (Governo) & 0 & $0 \%$ & 1 & $11 \%$ & 0 & $0 \%$ & 0 & $0 \%$ & 0 & $0 \%$ \\
\hline Participação em Feiras e Eventos & 0 & $0 \%$ & 0 & $0 \%$ & 1 & $11 \%$ & 2 & $22 \%$ & 3 & $33 \%$ \\
\hline Funcionários da Própria Empresa & 0 & $0 \%$ & 0 & $0 \%$ & 1 & $11 \%$ & 1 & $11 \%$ & 4 & $44 \%$ \\
\hline Funcionários de Outras Empresas (näo concorrentes) & 0 & $0 \%$ & 0 & $0 \%$ & 1 & $11 \%$ & 0 & $0 \%$ & 0 & $0 \%$ \\
\hline Funcionários dos Concorrentes & 0 & $0 \%$ & 1 & $11 \%$ & 0 & $0 \%$ & 0 & $0 \%$ & 0 & $0 \%$ \\
\hline Especialistas do Ramo & 0 & $0 \%$ & 0 & $0 \%$ & 0 & $0 \%$ & 0 & $0 \%$ & 0 & $0 \%$ \\
\hline Amigos, Parentes, Conhecidos, etc. & 0 & $0 \%$ & 1 & $11 \%$ & 0 & $0 \%$ & 1 & $11 \%$ & 3 & $33 \%$ \\
\hline Clientes & 0 & $0 \%$ & 0 & $0 \%$ & 3 & $33 \%$ & 3 & $33 \%$ & 5 & $56 \%$ \\
\hline Fornecedores & 2 & $22 \%$ & 0 & $0 \%$ & 0 & $0 \%$ & 1 & $11 \%$ & 0 & $0 \%$ \\
\hline
\end{tabular}

Fonte: dados da pesquisa.

Pela tabela 2 , percebe-se que os clientes $(56 \%)$ e os funcionários da própria empresa $(44 \%)$ são as fontes mais importantes para os gestores para tomada de decisão estratégica, seguidas pela televisão, rádio, participação em feiras e eventos, amigos, parentes e conhecidos com $33 \%$ cada um e com $22 \%$ as revistas especializadas. Os valores somam mais de $100 \%$, porque os respondentes puderam assinalar mais de uma opção.
Ressalta-se que os estudos setoriais do governo, funcionários de outras empresas (não concorrentes), funcionários dos concorrentes, especialistas do ramo e fornecedores não são as fontes de informações mais importantes para a decisão estratégica. Ao contrário, foram consideradas de média para baixa importância. Para os gestores, os especialistas do setor não representam nenhuma importância para a consecução de suas estratégias competitivas. Sugere-se que essa conclusão também seja aprofundada em futuras pesquisas.

TABELA 3

Fontes de informação e grau de confiabilidade

\begin{tabular}{|c|c|c|c|c|c|c|c|c|c|c|}
\hline \multirow[t]{2}{*}{ Tipos de fontes de informação } & \multicolumn{10}{|c|}{ Grau de confiança } \\
\hline & 1 & $\mathrm{Fr}$ & 2 & $\mathrm{Fr}$ & 3 & $\mathbf{F r}$ & 4 & $\mathrm{Fr}$ & 5 & $\mathrm{Fr}$ \\
\hline Televisão & 0 & $0 \%$ & 0 & $0 \%$ & 0 & $0 \%$ & 0 & $0 \%$ & 4 & $44 \%$ \\
\hline Rádio & 0 & $0 \%$ & 0 & $0 \%$ & 1 & $11 \%$ & 1 & $11 \%$ & 1 & $11 \%$ \\
\hline Jornais Impressos & 0 & $0 \%$ & 1 & $11 \%$ & 2 & $22 \%$ & 1 & $11 \%$ & 1 & $11 \%$ \\
\hline Revistas Especializadas & 0 & $0 \%$ & 0 & $0 \%$ & 2 & $22 \%$ & 2 & $22 \%$ & 1 & $11 \%$ \\
\hline Estudos setoriais (Governo) & 0 & $0 \%$ & 0 & $0 \%$ & 0 & $0 \%$ & 0 & $0 \%$ & 1 & $11 \%$ \\
\hline Participaçäo em Feiras e Eventos & 0 & $0 \%$ & 0 & $0 \%$ & 2 & $22 \%$ & 2 & $22 \%$ & 2 & $22 \%$ \\
\hline Funcionários da Própria Empresa & 0 & $0 \%$ & 0 & $0 \%$ & 1 & $11 \%$ & 0 & $0 \%$ & 2 & $22 \%$ \\
\hline Funcionários de Outras Empresas (não concorrentes) & 0 & $0 \%$ & 1 & $11 \%$ & 1 & $11 \%$ & 0 & $0 \%$ & 2 & $22 \%$ \\
\hline Funcionários dos Concorrentes & 0 & $0 \%$ & 0 & $0 \%$ & 0 & $0 \%$ & 1 & $11 \%$ & 1 & $11 \%$ \\
\hline Especialistas do Ramo & 0 & $0 \%$ & 0 & $0 \%$ & 0 & $0 \%$ & 0 & $0 \%$ & 1 & $11 \%$ \\
\hline Amigos, Parentes, Conhecidos, etc. & 0 & $0 \%$ & 0 & $0 \%$ & 1 & $11 \%$ & 0 & $0 \%$ & 3 & $33 \%$ \\
\hline Clientes & 0 & $0 \%$ & 0 & $0 \%$ & 1 & $11 \%$ & 3 & $33 \%$ & 3 & $33 \%$ \\
\hline Fornecedores & 0 & $0 \%$ & 1 & $11 \%$ & 0 & $0 \%$ & 1 & $11 \%$ & 1 & $11 \%$ \\
\hline
\end{tabular}

Fonte: dados da pesquisa. 
Quanto ao grau de confiabilidade dos gestores em relação às fontes de informações disponíveis para a tomada de decisão (ver tabela 3), a televisão aparece em primeiro lugar com $44 \%$ das respostas, seguida de amigos, parentes, conhecidos e clientes com 33\% cada uma. Esse dado corrobora as informações da tabela 1, principalmente no que tange às fontes de informações clientes e amigos, parentes e conhecidos. Fontes como participação em feiras e eventos, funcionários da própria empresa e funcionários de outras empresas também foram apontadas com alto grau de confiabilidade para significativa parcela dos gestores (22\%), seguidos pelas demais fontes, com $11 \%$ cada uma. De maneira geral, os gestores depositam considerável confiança nas fontes de informações utilizadas por eles em seus processos decisórios, apesar de não utilizarem todas.

A partir da análise das tabelas 2 e 3 , a tabela 4 foi delineada e serviu de base para a construção do gráfico 4 . Os indicadores foram selecionados com base na maior porcentagem de resposta fornecida pelos empreendedores. Por exemplo, para 20\% dos empreendedores (tabela 2), a fonte televisão tem grande
TABELA 4

Nível de importância e confiança das fontes de informação para a tomada de decisão estratégica

\begin{tabular}{lll}
\hline \multicolumn{1}{c}{ Fontes } & Importåncia & Confiança \\
\hline Televisăo & 5 & 5 \\
Rádio & 5 & 4 \\
Jomais Impressos & 4 & 3 \\
Revistas Especializadas & 4 & 4 \\
Estudos setoriais (Governo) & 2 & 5 \\
Participaçăo em Feiras e Eventos & 5 & 4 \\
Funcionários da Própria Empresa & 5 & 5 \\
Funcionários de Outras Empresas & 3 & 5 \\
(näo concorrentes) & & \\
Funcionários dos Concorrentes & 2 & 5 \\
Especialistas do Ramo & 0 & 5 \\
Amigos, Parentes, Conhecidos, etc. & 5 & 5 \\
Clientes & 5 & 5 \\
Fornecedores & 1 & 4 \\
\hline
\end{tabular}

Fonte: dados da pesquisa (tabelas 2 e 3)

importância (valor 5) e 44\% de confiança (tabela 3) (valor 5). As demais fontes foram classificadas utilizando-se o mesmo sistema. Em caso de dois ou mais valores iguais, optou-se pelo valor médio.

\section{GRÁFICO 4}

Importância versus confiança das fontes de informações utilizadas na tomada de decisão estratégica

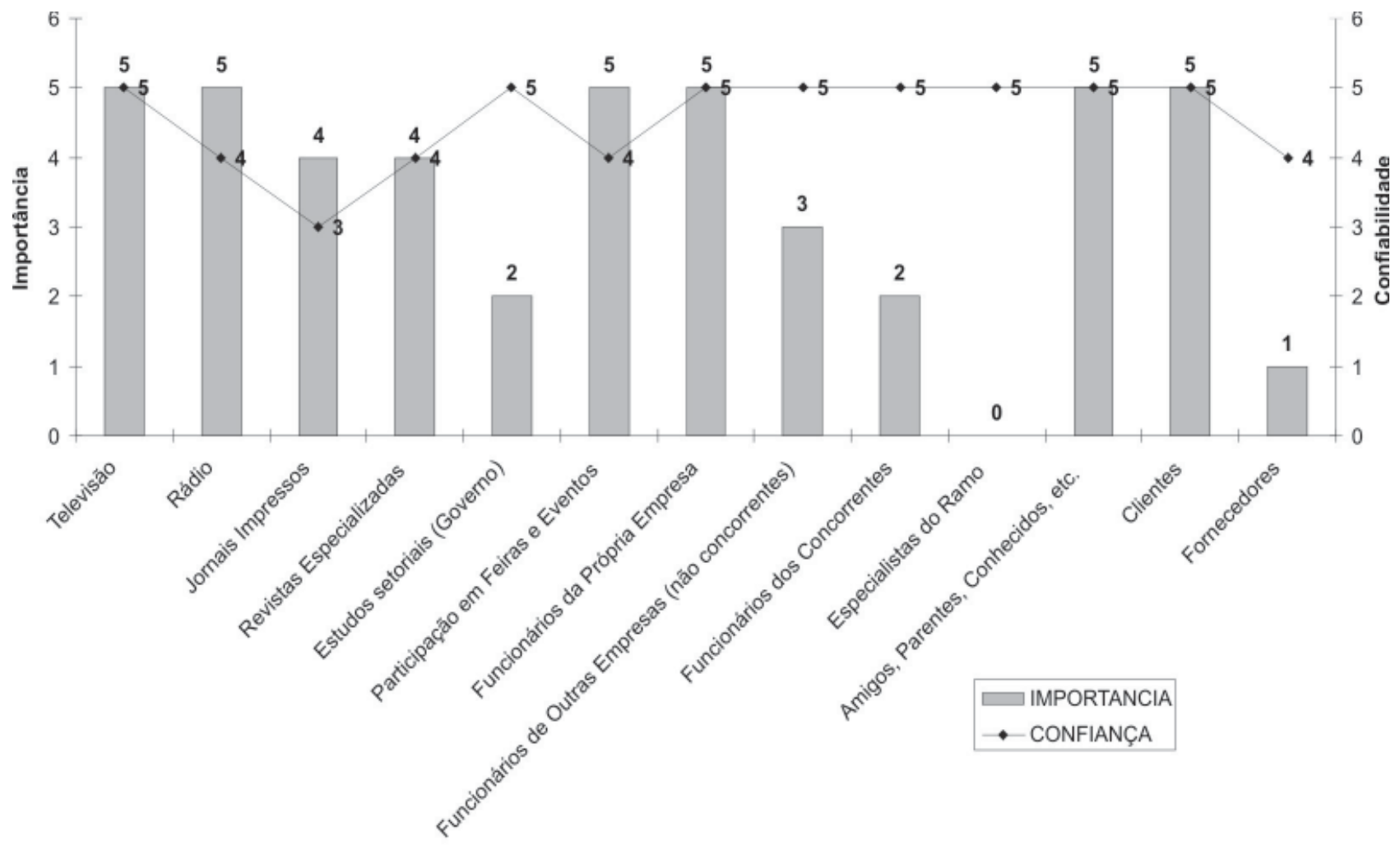

Fontes de Informação

Fonte: dados da pesquisa (tabela 4). 
Pela análise do gráfico 4, percebe-se que as fontes televisão, clientes, amigos, parentes, conhecidos e os funcionários da própria empresa apresentaram os maiores níveis de importância e confiabilidade para a tomada de decisão, e, como essas fontes são utilizadas pelos gestores diariamente (ver tabela 1), é aconselhável que mantenham estruturas que facilitem e estimulem continuamente o fluxo de informação proveniente de tais fontes, a fim de propiciar melhores condições para a busca da eficácia do seu processo decisório. As fontes rádio, jornais impressos, revistas especializadas, participação em feiras e eventos também merecem especial atenção, apesar de sua média freqüência de utilização.

É importante destacar que os estudos setoriais do governo, funcionários de outras empresas não concorrentes, funcionários dos concorrentes e os fornecedores da empresa não apresentaram importância para a tomada de decisão na percepção dos gestores, apesar de manterem um nível de confiança elevado. Por último, atribuíram alto grau de confiança aos especialistas do setor (consultores, experts, entre outros), apesar da sua baixa importância para a tomada de decisão. Esse dado é comprovado pela tabela 1, ao constatar-se que os gestores normalmente não utilizam tal fonte de informação para a tomada de decisão estratégica.

\section{CONSIDERAC̣ÕES FINAIS E RECOMENDAÇÕES}

Estudos sobre monitoramento ambiental têm ressaltado a importância de se manter um fluxo contínuo de informações entre a organização e o seu ambiente de negócios (AGUILAR 1967, CHOO, 1995; PORTER, 1999, KOTLER, 2000; MINTZBERG, 2003). A partir das conclusões dos estudos sobre as influências do ambiente sobre o funcionamento e a gestão organizacional (CHANDLER, 1962; BURNS; STALKER, 1961; LAWRENCE; LORSCH, 1967), percebe-se que a escolha eficaz de fontes de informações ajuda os gestores a tomar melhores decisões estratégicas, minimizando os riscos derivados do aumento da complexidade e da dinamicidade do ambiente competitivo (incertezas).

Para muitos autores, entre eles Porter (1980), Drucker (1995, 1999), Davenport e Prusak (1998) e Kotler (2000) informações rápidas, precisas, confiáveis e oportunas podem ajudar as organizações a sobreviver e a crescer sustentavelmente em ambientes em constante mutação. Auster e Choo (1995), Nonaka e Takeushi (1997) e Senge (1999), por exemplo, têm apostado na gestão do conhecimento e na aprendizagem organizacional como instrumentos e práticas eficazes para vencer os desafios e as ameaças impostas pelo atual contexto ambiental.

Partindo-se da constatação do aumento da competição no setor varejista da capital mineira (FECOMÉRCIO Minas, 2008), o presente artigo analisou o comportamento informacional para a tomada de decisão estratégica dos micro e pequenos empreendedores instalados na região do Barro Preto em Belo Horizonte. Os resultados permitem concluir que existe forte compreensão sobre a complexidade e dinamicidade do ambiente competitivo no qual os seus empreendimentos estão instalados. Para a maioria deles, há elevado número de concorrentes diretos e indiretos que lançam produtos freqüentemente no mercado.

Segundo dados fornecidos, pode-se concluir também que o setor apresenta baixa barreira de entrada a novos competidores no mercado, o que cria as condições necessárias para o delineamento de um cenário cada vez mais competitivo, haja vista a entrada e saída freqüente de competidores no mercado.

Associando-se essas conclusões aos estudos de Duncan (1972) e Mintzberg (2003) sobre tipologias ambientais, verifica-se que há incerteza até certo ponto elevada no setor, o que normalmente aumenta a demanda dos gestores por informações rápidas, precisas e confiáveis sobre fatos, eventos, tendências e relacionamentos que acontecem nos seus ambientes de negócios (DRUCKER, 1995, 1999; DUNCAN, 1972; PORTER, 1980; KOTLER, 2000; MINTZBERG, 2003).

Quanto às fontes de informações utilizadas pelos gestores para a tomada de decisão estratégica, constatou-se o uso intenso e diário das fontes como clientes, amigos, parentes, conhecidos e funcionários da própria empresa. Esse fato pode ser explicado, a priori, pela facilidade e rapidez de acesso a tais fontes, o que pode ser mais bem analisado por pesquisas posteriores. Na mesma linha de raciocínio, fontes como participação em eventos e feiras, televisão e rádio e revistas especializadas também apresentaram relevância para os empreendedores.

Entretanto, é importante destacar algumas fontes que, apesar de serem bastante analisadas em outros trabalhos acadêmicos, não apresentaram expressivo resultado nesta pesquisa. A primeira delas refere-se ao uso de especialistas (consultores, experts, e outros) como fontes de informação para a tomada de decisão. Os dados demonstraram que os empreendedores normalmente não utilizam esse tipo de fonte, apesar de confiarem nela. 
Outra conclusão importante se refere à baixa utilização dos fornecedores e dos funcionários de outras empresas (concorrentes ou não) como fontes de informação para o delineamento de estratégias competitivas. Por ser um ambiente altamente competitivo, esse dado representou certa inconsistência, o que também poderá ser analisado em futuras pesquisas.

Em síntese, conclui-se que o terceiro milênio configurará um novo tempo para as micro e pequenas empresas do comércio varejista de Belo Horizonte. Elas enfrentarão ambientes cada vez mais complexos, dinâmicos e imprevisíveis. Entra-se em uma época marcada por incertezas e pelo aumento da complexidade ambiental, caracterizada pelo aumento da pressão por parte dos consumidores, competidores, fornecedores, investidores, governos e pela sociedade em geral.

Como conseqüência disso, percebe-se crescente necessidade dos gestores varejistas por informações confiáveis, rápidas e consistentes que lhes forneçam os insumos necessários para a construção do conhecimento e da inteligência necessários ao processo de tomada de decisão estratégica cada vez mais eficiente e eficaz. Para tanto, aconselha-se que as organizações mantenham um processo contínuo de monitoração do ambiente competitivo no qual estão inseridas, na tentativa de evitar surpresas que coloquem em risco a sua sobrevivência e o seu crescimento nos mercados em que atuam ao longo do tempo.

Artigo submetido em 25/09/2008 e aceito em 22/12/2008.

\section{REFERENNCIAS}

1. AGUILAR, F. J. Scanning the business environment. New York: The Macmillan Company, 1967.

2. AUSTER, E.; CHOO, C. W. CEOs, information, and decisionmaking: scanning the environment for strategic advantage. Library Trends, v. 43, n. 2, p. 206-225, Fall 1994.

3. BARBOSA, R. R. Monitoração ambiental: uma visão interdisciplinar. Revista de Administração, v. 32, n. 4, p. 42-53, out./ dez. 1997.

4. Inteligência empresarial: uma avaliação de fontes de informação sobre o ambiente organizacional externo. Datagrama Zero - Revista de Ciência da Informação, v. 3, n. 6, dez. 2002.

5. BURNS, T.; STALKER, G. M. The management of innovation. London: Tavistock, 1961.

6. BORGES, M. E. N. A informação como recurso gerencial das organizações na sociedade do conhecimento. Ciência da Informação, v. 24, n. 2, p. 181-188, maio/ago. 1995.

7. BUCHKO, A. A. Conceptualization and Measurement of Environmental Uncertainty: an assessment of the miles and snow perceived environmental uncertainty scale. Academy of Management Journal, v. 37, n. 2, p. 410-425, 1994.

8. CHANDlER, A. Strategy and structure. Cambrige, MA: MIT Press, 1962.

9. $\mathrm{CHOO}, \mathrm{C}$. W. Information management for the intelligent organization. Medford, NJ: Information Today, 1995.

10. COllis, J.; HUSSEY, R. Pesquisa em administração. 2. ed. Porto Alegre: Bookman, 2005.

11. DAFT, R.L. Organizações: teorias e projetos. São Paulo: Pioneira Thomson Learning, 2002.

12. ______; SORMUNE, J.; PARKS, D. Chief executive scanning, environmental characteristics, and company performance: an empirical study. Strategic Management Journal, v. 9, n. 2, p. 123-139, 1988.

13. ; LENGEL, R. Organizational information requirements, media richness and structural design. Management Science, v. 32, n. 4, p. 554-571, May 1986.

14. D’AVENI, Richard. Hipercompetição. Rio de Janeiro: Campus, 1995.

15. DAVENPORT, T. Ecologia da informação. São Paulo: Futura, 1998.

16. ___ PRUSAK, L. Conhecimento empresarial. Rio de Janeiro: Campus, 1998.

17. DILL, W. R. Environment as an influence on managerial autonomy. Administrative Science Quarterly, v. 2, n. 4, p. 409-443, 1958.

18. DRUCKER, P. Desafios gerenciais para o século XXI. São Paulo: Pioneira, 1999.

19. ___ The information executives truly need. Harvard Business Review, Jan./Feb. 1995.

20. DUNCAN, R. Characteristics of organizational environments and perceived environmental uncertainty. Administrative Science Quarterly, v. 17, n. 3, p. 313-327, 1972. 
Contexto competitivo, monitoramento ambiental e tomada de decisão estratégica: o caso dos micro e pequenos varejos da região do Barro Preto em Belo Horizonte

21. EMERY, F. E.; TRIST, E. L., The causal texture of organizational environments. Human Relations, v. 18, p. 21-32, 1965.

22. FECOMERCIO MINAS. Federação do Comércio de Minas Gerais. Disponivel em: 〈http://www.fecomerciomg.org.br/>. Acesso em: 10 abr. 2008

23. HAMBRICK, D. C. Environmental scanning and organizational strategy. Strategic Management Journal, v. 13, n. 2, p. 44-49, 1982.

24. HAMEL, G; PRAHALAD, C. K. Competing for the future: breakthrough strategies for seizing control of your Industry and creating. Boston, MA: Harvard Business School Press, 1994

25. KOTLER, P. Administração de marketing: análise, planejamento, implementação e controle. 10. ed. São Paulo: Atlas, 2000.

26. LAWRENCE, P. R.; LORSCH, J. W. Organization and environment: managing differentiation and integration. Boston, MA: Harvard University Press, 1967.

27. MINTZBERG, H. Criando organizações eficazes. 2. ed. São Paulo: Atlas, 2003
28. MORESI, E. A D. Inteligência organizacional: um referencial integrado. Ciência da Informação, Brasília, v. 30, n. 2, p. 35-46, mai./ ago. 2001.

29. NADLER, D. A. et al. Arquitetura organizacional: a chave para a mudança empresarial. Rio de Janeiro: Campus, 1993.

30. NONAKA, I.; TAKEUCHI, H. Criação do conhecimento na empresa. Rio de Janeiro: Campus, 1997.

31. PORTER, M. Competitive strategy: techniques for analyzing industries and competitors. New York: The Free Press, 1980.

32. Estratégias competitivas essenciais. Rio de Janeiro: Campus, 1999.

33. SENGE, P. M. A quinta disciplina: arte, teoria e prática da organização de aprendizagem. São Paulo: Best Seller, 1999.

34. SUTTON, H. Competitive intelligence. New York: The Conference Board, 1988. (Conference Board Research Report, n. 913).

35. BARBOSA, R. R. Inteligência empresarial: uma avaliação de fontes de informação sobre o ambiente organizacional externo. Datagrama Zero - Revista de Ciência da Informação, v. 3, n. 6, dez. 2002. 